OPEN ACCESS

Edited by: Juergen Prattes,

Medizinische Universität Graz, Austria

Reviewed by:

P. Lewis White,

Public Health Wales NHS Trust,

United Kingdom

Juergen Loeffler,

University Hospital Würzburg,

Germany

*Correspondence:

Peter-Michael Rath

pm.rath@uni-due.de

Specialty section:

This article was submitted to Fungi and Their Interactions,

a section of the journal

Frontiers in Microbiology

Received: 30 January 2018

Accepted: 29 March 2018

Published: 24 April 2018

Citation:

Rath P-M and Steinmann J (2018) Overview of Commercially Available

PCR Assays for the Detection

of Aspergillus spp. DNA in Patient

Samples. Front. Microbiol. 9:740.

doi: 10.3389/fmicb.2018.00740

\section{Overview of Commercially Available PCR Assays for the Detection of Aspergillus spp. DNA in Patient Samples}

\author{
Peter-Michael Rath ${ }^{1 *}$ and Joerg Steinmann ${ }^{1,2}$ \\ 1 Institute of Medical Microbiology, Essen University Hospital, University of Duisburg-Essen, Essen, Germany, \\ ${ }^{2}$ Institute of Clinical Hygiene, Medical Microbiology and Infectiology, Paracelsus Medical University, Klinikum Nuernberg, \\ Nuremberg, Germany
}

Invasive aspergillosis (IA) is a life-threatening infection in immunocompromised patients. Early diagnosis is essential to improve survival. Since the 1990s, attempts for PCR-based diagnosis of IA were made. Progress in the standardization of methods enabled the development of commercially available Aspergillus PCR assays in the last few years. Up to now, the clinical value of only a few commercial assays was investigated more extensively in large cohort studies. Most often, respiratory secretions such as bronchoalveolar lavage (BAL) were investigated, but some studies also included serum samples from high-risk patients. The data indicate that Aspergillus PCR, most likely in combination with galactomannan detection, has the potential for early and reliable diagnosis of IA including azole resistance markers. With the broad implementation of this technique in routine diagnosis and incorporation into patient care pathways, it is conceivable that an improvement in management of IA and subsequently patient outcome could occur.

Keywords: Aspergillus, aspergillosis, PCR, laboratory diagnosis, azole resistance

\section{INTRODUCTION}

Aspergillosis, which is defined as an infection or disease caused by fungi of the genus Aspergillus, mainly affects immunocompromised and critically ill patients and invasive disease is associated with high mortality. Conventional diagnosis is difficult and there is a widespread use of prophylaxis and empirical antifungal treatment in the management of invasive disease despite a relatively low incidence. Furthermore, the global emergence of infections with azole-resistant Aspergillus fumigatus (Steinmann et al., 2015; Verweij et al., 2016), associated with therapeutic failure, strengthened the need for rapid and reliable diagnostic methods.

The conventional diagnosis of Aspergillus infections is based on the presence of risk factors, radiological features, and microbiological results, i.e., histopathology and/or culture of Aspergillus spp. A milestone was the standardization of the classification of disease based on probability of aspergillosis [i.e., proven, probable, or possible invasive fungal disease according to the definitions of the European Organization for Research and Treatment of Cancer/Invasive Fungal Infections Cooperative Group and the National Institute of Allergy and Infectious Diseases Mycoses Study 
Group (EORTC/MSG; De Pauw et al., 2008)]. These criteria are the basis for determining drug efficacy, validation of diagnostic tests, and epidemiological analyses. Primarily established for the classifications of patients in clinical and laboratory studies, these definitions can also be very useful in clinical settings. However, they were established for hemato-oncological settings and modifications were necessary to fit also other patients groups like intensive care unit (ICU) patients (Meersseman et al., 2004; Blot et al., 2012). The microbiological criteria are a positive histopathology, microscopy, or culture of primarily sterile samples, defining a proven infection, and the detection of the antigens galactomannan and (1-3)- $\beta$-D-glucan in serum or other body fluids such as bronchoalveolar lavage (BAL; De Pauw et al., 2008). PCR assays were not included in 2008, but will be included in the next/current version. In recent years, Aspergillus PCR has been shown, in combination with other biomarkers, to be a promising tool in diagnostic algorithms as reviewed recently, for example, by White et al. (2015b), Buchheidt et al. (2017), and Lamoth and Calandra (2017).

Since the 1990s, several studies were published on inhouse PCR assays to detect Aspergillus DNA in clinical samples. These studies showed in nearly all cases a higher sensitivity than in cultures, particularly in immunocompromised patients. However, the assays differed markedly in sample preparation, target, platforms (Buchheidt et al., 2017), and consequently in sensitivity and specificity (Arvanitis et al., 2015; White et al., 2015b). Since 2006, major progress was made in the standardization of PCR assays for the detection of Aspergillus-DNA in clinical samples by the European Aspergillus PCR Initiative (EAPCRI) Working Group of the International Society of Human and Animal Mycoses (ISHAM; White et al., 2011a). A meta-analysis reported a higher accuracy to diagnose invasive aspergillosis (IA) for those PCR studies, compliant with the EAPCRI recommendations (Arvanitis et al., 2014). The advances in the standardization of clinical criteria and laboratory procedures show that PCR is now sufficiently robust for routine Aspergillus diagnostics. Consequently, commercial PCR assays such as AsperGenius ${ }^{\circledR}$ (PathoNostics, Maastricht, Netherlands), MycAssay Aspergillus ${ }^{\circledR}$ (Myconostica Ltd., Cambridge, United Kingdom), MycoReal Aspergillus ${ }^{\circledR}$ (ingenetix $\mathrm{GmbH}$, Austria), RenDX Fungiplex ${ }^{\circledR}$ (Renishaw Diagnostics Ltd., Glasgow, United Kingdom), MycoGenie ${ }^{\circledR}$ (Ademtech, Pessac, France), LightCycler SeptiFast ${ }^{\circledR}$ (Roche Molecular Diagnostics, Penzberg, Germany), GeneProof Aspergillus $\mathrm{PCR}^{\circledR}$ (Brno, Czechia), Aspergillus spp. Alert Kit ${ }^{\circledR}$ (Nanogen, now ELITechGroup, Turin, Italy), Aspergillus Real-time PCR Panel $^{\circledR}$ (Viracor Eurofins, Framingham, MA, United States), A. fumigatus $^{\circledR}$ Bio-Evolution (Bio-Evolution, Bry-sur-Marne, France), and Fungiplex Aspergillus ${ }^{\circledR}$ (Bruker Daltonik GmbH, Bremen, Germany) became available in recent years. For only some of these assays data on the sensitivity and specificity for diagnosing IA are currently available. The performances of the PCR assays will be discussed in the following. In Table 1 an overview on the performance of the assays in prospective studies is given.

\section{MycAssay Aspergillus ${ }^{\circledR}$}

The MycAssay Aspergillus ${ }^{\circledast}$, developed by Myconostica Ltd. (Cambridge, United Kingdom), now Microgen Bioproducts Ltd. (Camberley, United Kingdom), is a real-time PCR it for use on the Cepheid SmartCycler, Roche LightCycler 2.0, Stratagene Mx3000, AB 7500, or BioRad CFX96 platforms. The target is the $18 \mathrm{~S} \mathrm{rDNA}$ and the detection limit is less than 50 target copies. The assay detects different Aspergillus spp. including A. fumigatus. Torelli et al. (2011) investigated the usefulness of the MycAssay Aspergillus ${ }^{\circledR}$ in comparison with an in-house PCR and galactomannan detection in hematological $(N=68)$ and nonhematological $(N=90)$ patients using BAL samples. Most of the patients (89.9\%) were neutropenic and were classified as proven, probable, or possible aspergillosis using the EORTC/MSG criteria or the modifications suggested by Meersseman et al. (2004). Two proven and 15 probable cases were found. The control group consisted of 141 patients. The sensitivity, specificity, positive predictive value (PPV), and negative predictive value (NPV) were $94.1 \%, 98.6 \%, 88.9 \%$, and $99.3 \%$. Nearly identical data were found by using the galactomannan assay (index cutoff of $\geq 1$ ).

Guinea et al. (2013) investigated 322 respiratory samples from 175 patients without hemato-oncological diseases, of which 15 had probable IA. Sensitivity, specificity, PPV, and NPV were $86.7 \%, 87.6 \%, 34.1 \%$ and $92.2 \%$. Culture was positive in 65 samples of 35 patients.

Orsi et al. (2012) evaluated the performance of the MycAssay Aspergillus $^{\circledast}$ in BAL samples of 20 hematological and nonhematological immunosuppressed patients, including seven suffering from IA. All patients with proven or probable aspergillosis were positive by PCR (100\% sensitivity).

In a larger study (Orsi et al., 2015), the MycAssay Aspergillus ${ }^{\circledast}$ was compared with galactomannan and culture in BAL samples from 41 patients (44 samples) at risk for infection along with assays for the detection of Pneumocystis jirovecii. Patients were in part hemato-oncological patients, for which the EORTC/MSG criteria were used (De Pauw et al., 2008), for patients with other underlying diseases additional host factors, such as steroid treatment, chronic obstructive pulmonary disease, lower respiratory infections, and new infiltrates were applied. Ten patients were diagnosed as probable infected with molds. Culture of BAL was positive in $6 / 10$ patients and all had a positive galactomannan in BAL. PCR was positive in $8 / 10$ patients, and in $1 / 34$ of control patients. The authors calculated for the PCR assay a sensitivity of $80 \%$, a specificity of $97.1 \%$, a PPV of $88.9 \%$, and a NPV of $94.3 \%$.

White et al. (2011b) compared the sensitivity and specificity of the assay and an in-house assay using 170 serum samples from patients (104 samples of 10 patients with proven or probable IA and 66 samples from 21 patients at risk for IA). Seven of the 10 patients with proven/probable IA were positive in at least one sample. The MycAssay Aspergillus ${ }^{\circledR}$ showed a sensitivity of 60 to $70 \%$ and a specificity of $90.5 \%$ to $100 \%$, which was comparable to the in-house assay.

Pini et al. (2015) compared the MycAssay Aspergillus ${ }^{\circledast}$ in serum with the galactomannan assay in 71 episodes of 64 hematological and non-hematological patients (30 
TABLE 1 | Overview of published prospective studies on commercial available PCR assays for Aspergillus detection.

\begin{tabular}{|c|c|c|c|c|c|c|}
\hline Assay (Detected species) & $\begin{array}{l}\text { Sample type } \\
\text { (no. of samples/patients) }\end{array}$ & Sensitivity & Specificity & Patients & $\begin{array}{l}\text { No. of patients with } \\
\text { proven/probable IA }\end{array}$ & Reference \\
\hline MycAssay & $\mathrm{BAL}(158 / 158)$ & $94.1 \%$ & $98.6 \%$ & Mixed & 17 & Torelli et al., 2011 \\
\hline \multirow{4}{*}{$\begin{array}{l}\text { Aspergillus (Aspergillus spp., } \\
\text { Penicilliurn spp.) }\end{array}$} & Resp. samples (322/175) & $86.7 \%$ & $87.6 \%$ & Non-hematology & 15 & Guinea et al., 2013 \\
\hline & $\operatorname{BAL}(44 / 41)$ & $80 \%$ & $97.1 \%$ & Mixed & 10 & Orsi et al., 2015 \\
\hline & Serum $(71 / 64)$ & $46.7 \%$ & $97.6 \%$ & Mixed & 30 episodes & Pini et al., 2015 \\
\hline & Serum (358/78) & $75 \%$ & Not given & Hematology & 18 & Oz et al., 2016 \\
\hline AsperGenius & BAL (201/201) & $84 \%$ & $80 \%$ & Hematology & 52 & Chong et al., 2016 \\
\hline $\begin{array}{l}\text { (A. fumigatus complex, A. terreus, } \\
\text { Aspergillus spp.; TR34, L98H, } \\
\text { Y121F, T289A) }\end{array}$ & $\mathrm{BAL}(387 / 387)$ & $68.4 \%$ & $>92 \%$ & "at high risk" & 38 & Guegan et al., 2018 \\
\hline $\begin{array}{l}\text { MycoGenie } \\
\text { (A. fumigatus; TR34/L98H) }\end{array}$ & $\mathrm{BAL}(387 / 387)$ & $71.1 \%$ & $>92 \%$ & "at high risk" & 38 & Guegan et al., 2018 \\
\hline
\end{tabular}

episodes were classified as IA). Classification was done based on the EORTC/MSG criteria for the hematological patients and on the criteria proposed by Meersseman et al. (2004) for non-hematological patients. Sensitivity, specificity, PPV and NPV for the MycAssay Aspergillus ${ }^{\circledR}$ were $46.7 \%, 97.6 \%, 93.3 \%$, and $71.4 \%$. These numbers were similar to those for the galactomannan assay. When considering hematological patients only, the sensitivity increased to $60 \%$.

Danylo et al. (2014) compared the MycAssay Aspergillus ${ }^{\oplus}$ in serum with galactomannan using 146 serum samples of 35 patients with hematological malignancies. Four patients suffered from a proven infection, 12 patients from a probable infection, and 13 patients were not infected. Sensitivity, specificity, PPV, and NPV were 25\%, 83.3\%, $39.3 \%$, and $72 \%$. The relative low sensitivity might be a result of a high proportion of patients under antifungal treatment in the proven/probable group (14/16 patients). The galactomannan assay showed a higher specificity (93.1\%).

Another recent study also tested the MycAssay Aspergillus ${ }^{\circledR}$ in comparison with an in-house PCR and galactomannan in 358 sera from 78 febrile neutropenic episodes in patients with IA and 83 episodes in patients with no IA (Oz et al., 2016). The topic of this study was the investigation of factors that can influence test results. The hospitalization period, duration of neutropenia, and T-cell suppression were significantly higher in the IA group. Even though there were no significant differences in test performances, the use of larger volumes $(>500 \mu \mathrm{l})$ of sera improved the performance of the commercial PCR assay.

Taken together, the MycAssay Aspergillus ${ }^{\circledR}$ showed a very good performance in BAL samples, especially for patients with hematological malignancies. The accuracy in the serum was not better than galactomannan.

Aquino et al. (2012) compared the performance of two commercial real-time PCR assays and galactomannan in BAL of 47 ventilated patients with chronic obstructive pulmonary disease. The included assays were the MycAssay Aspergillus ${ }^{\circledR}$ and the Aspergillus spp. q-PCR Alert ${ }^{\circledR}$ Kit (ELITechGroup, Turin, Italy). The Aspergillus spp. q-PCR kit, which is a quantitative real-time PCR with a target within the $28 \mathrm{~S}$ rDNA, detected one of two patients with positive Aspergillus culture and positive galactomannan. The MycAssay Aspergillus ${ }^{\circledR}$ was positive in 10 patients including the two with positive culture.

\section{AsperGenius $^{\circledR}$}

The AsperGenius ${ }^{\circledR}$ assay is a multiplex real-time PCR assay developed by PathoNostics (Maastricht, Netherlands). It runs on LightCycler 480, Rotor-Gene 6000 (Corbett) and Rotor-Gene Q (Qiagen). Two PCR assays for respiratory secretions are available, one for the detection and differentiation of Aspergillus spp., targeting the 28Sr DNA [AsperGenius Species multiplex $^{\circledast}$ with a probe for the A. fumigatus complex (including A. fumigatus, A. lentulus, A. udagawae, and A. viridinutans), a probe for Aspergillus spp. (including A. fumigatus complex, A. terreus, A. flavus, and A. niger), and one (AsperGenius Resistance multiplex ${ }^{\circledR}$ )] for the detection of four azole resistance markers within the Cyp51A gene of A. fumigatus (L98H, TR34, T289A, Y121F).

Chong et al. (2015) investigated BALs from 10 hematologic and 12 non-neutropenic patients. For neutropenic patients the EORTC/MSG criteria were used, and most of the nonneutropenic patients and some hematological patients were classified as non-classifiable. There was one proven IA case. Sensitivity, specificity, PPV, and NPV were $84.2 \%, 91.4 \%, 76.2 \%$, $96.6 \%$, respectively. In two cases azole-resistant strains were found.

A multicenter study from 2016 aimed to validate the assay by using stored BAL samples from patients with hematological diseases with suspected IA (Chong et al., 2016). From a total of 201 included samples, 88 were positive and 113 were negative controls. A cut-off value of $<38$ cycles was used. The diagnostic performance was the following: sensitivity $84 \%$, specificity $80 \%$, PPV 76\%, and NPV 87\%. In eight samples, a resistant mutation was detected. Mortality was 2.7 times higher in patients with isolates with azole-resistant mutations.

The assay was also tested by Schauwvlieghe et al. (2017) using BAL samples from 91 patients from Netherlands with positive galactomannan in BAL and suspected invasive Aspergillus infection. In 79\% DNA of A. fumigatus or Aspergillus spp. was detected. A mutation associated with azole resistance was 
detected in eight cases $\left(\mathrm{TR}_{34} / \mathrm{L} 98 \mathrm{H}\right)$ and in three patients, T289A/Y121F alterations were found.

Montesinos et al. (2017) evaluated the assay by using BAL from 100 patients including 29 patients (cystic fibrosis, lung transplant recipients) with proven or probable aspergillosis. Twenty-seven patients were positive for Aspergillus spp. DNA and 20 patients for A. fumigatus DNA. Three of them harbored mutations in the Cyp51A gene (one patient with colonization only).

In a retrospective study White et al. (2015a) investigated 124 serum samples of 49 hemato-oncological patients (14 proven/probable cases, 33 control patients). Sensitivity was $78.6 \%$ and specificity $100 \%$. No resistance markers were found.

In a larger study, the same group (White et al., 2017) investigated 211 plasma samples from 10 patients with proven or probable IA, two possible cases and 27 controls. Sensitivity and specificity was $80 \%$ and $77.8 \%$. If more than one positive sample was required for being relevant, the specificity increased to $100 \%$, but sensitivity dropped to $50 \%$.

Based on the existing studies, the AsperGenius ${ }^{\circledR}$ assay had a good diagnostic utility. An innovative advantage of this of the assay is the ability to detect azole-resistant mutations.

\section{MycoGenie $^{\infty}$}

The MycoGenie ${ }^{\circledR}$ assay, developed by AdemTech (Pessac, France) detects $A$. fumigatus based on the $28 \mathrm{~S}$ rDNA, and the TR34/L98H mutation. Recommended materials are biopsies and respiratory and serum samples. The platforms are CFX96, ABI 7500, LightCycler 480, SmartCycler, MX3000, and the Rotor-Gene. Recently Dannaoui et al. (2017) validated the assay using 88 respiratory samples (59 culture positive) and 69 serum samples (from 16 patients) with proven or probable aspergillosis. Sensitivity and specificity was $92.9 \%$ and $90.1 \%$ for the respiratory samples, and $100 \%$ and $84.6 \%$, respectively, for serum samples, when analyzing samples at the time of clinical diagnosis.

A large study by Guegan et al. (2018) from France compared the MycoGenie ${ }^{\circledast}$ assay with the AspergGenius ${ }^{\circledR}$ assay and two in-house assays included BAL samples from 387 hematological and non-hematological patients. One patient suffered from a proven infection, 37 patient cases were classified as probable, and 23 as possible IA. The MycoGenie ${ }^{\circledR}$ assay showed a sensitivity of $53.7 \%$ in patients $(n=41)$ with hemato-oncological diseases, and a sensitivity of $75 \%$ in the 20 patients with non-hematological diseases. The AspergGenius ${ }^{\circledR}$ assay showed a lower sensitivity of $41.5 \%$ in the hematological patients compared to $60 \%$ in the non-hematological patients. Not surprisingly, the sensitivity of all assays was lower in patients with antifungal prophylaxis (36-45\% vs. 50-62\%) or treatment (35-40\% vs. $53-70 \%)$. Due to the study design, data on the specificity of the assays were not collected (analysis samples of patients with IA only). Interestingly, resistance markers were not found.

The assay was also used for molecular detection of Aspergillus in French patients with clinically diagnosed fungal rhinosinusitis and positive microscopy $(N=137)$, most of them with fungal ball as clinical manifestation (Morio et al., 2018). In 77.4\% of the patients the assay gave positive results compared with $32.1 \%$ culture positivity. Again, no resistance markers were found.

In a recently published study, the MycoGenie ${ }^{\circledR}$ assay was compared with the A. fumigatus Bio-Evolution ${ }^{\circledR}$ assay (Bio-Evolution ${ }^{\circledR}$, Bry-sur-Marne, France). The A. fumigatus Bio-Evolution assay uses the ITS1 region for specific detection of A. fumigatus DNA. In the retrospective study by Denis et al. (2018), 73 BAL samples from hematological and nonhematological patients, previously used for $P$. jirovecii PCR, were retrospectively analyzed. Thirty-one patients were classified as probable IA, 11 as probable IA, and 31 patients as control group. Both assays showed a $100 \%$ specificity and a sensitivity of 81\% (A. fumigatus Bio-Evolution assay) and 71\% (MycoGenie ${ }^{\circledR}$ assay). Interestingly, antifungal treatment had no influence on sensitivities. No resistance markers were found.

In summary, the diagnostic performance of this new assay is promising; also the possibility to detected one of the most common azole resistant mutation is advantageous. More data is needed to give a final rating about the utility in the clinical routine.

\section{SeptiFast ${ }^{\circledR}$}

The SeptiFast ${ }^{\circledast}$ assay is a multiplex-real-time PCR for the detection of a spectrum of bacterial and fungal pathogens in whole blood. Besides Candida albicans, Candida tropicalis, Candida parapsilosis, Candida krusei, and Candida glabrata, it also detects A. fumigatus. With respect to bacterial pathogens, the system showed a sensitivity and specificity of $68 \%$ and $86 \%$ when compared to blood culture (Dark et al., 2015).

A retrospective study by Steinmann et al. (2016) analyzed the diagnostic performance for A. fumigatus detection and the relevance of the assay in whole blood from critically ill ICU patients with probable or proven IA $(N=38)$ and without IA $(N=100)$. Modifications of the EORTC/MSG criteria (additional risk factor: an ICU stay longer than 4 days) were used to classify the patients. The assay showed in these patients a sensitivity of $66 \%$ and a specificity of $98 \%$, a PPV of $93 \%$, and an NPV of $88 \%$. One important result was the high mortality in patients with positive PCR.

The accuracy of the SeptiFast ${ }^{\circledast}$ assay for whole blood was very good. However, the disadvantages of this assay are the laborious workflow and the higher costs compared to other species-specific PCR tests.

\section{RenDx Fungiplex ${ }^{\circledR}$}

The RenDX Fungiplex ${ }^{\circledR}$ assay (Renishaw Diagnostics Ltd Glasgow, United Kingdom) is based on a PCR targeting sequences of the $18 \mathrm{~S}$ rDNA and $28 \mathrm{~S}$ rDNA, followed by a surfaceenhanced Raman scattering (SERS) for the sensitive detection of pathogen-specific oligonucleotides. It used an Aspergillus probe in combination with a broad-range Saccharomycetales probe to simultaneously detect Aspergillus and Candida spp. White et al. (2014) validated this assay, using plasma samples from 14 mostly hemato-oncological patients with proven/probable IA and 80 
patients without IA. Sensitivity was $82.2 \%$ and specificity $87.5 \%$. The RenDX Fungiplex ${ }^{\circledR}$ has been reformatted to utilize realtime PCR technology. Results concerning the clinically utility of the Fungiplex Aspergillus $\mathrm{PCR}^{\circledR}$ assay (Bruker Daltonik $\mathrm{GmbH}$, Bremen, Germany) are so far not available. However, first results with spiked samples showed an excellent analytical performance in the detection of DNA of A. fumigatus, Aspergillus flavus, Aspergillus niger, and Aspergillus terreus (Green and Dougan, 2017).

\section{CONCLUSION}

A number of commercial tests to detect Aspergillus spp. in clinical samples are available, but only a few have been currently (March 2018) validated independently from the manufacturers. Nevertheless, based on the published data so far, the mentioned assays seem to have comparable sensitivities and specificities. Overall, sensitivity is significantly lower in

\section{REFERENCES}

Aquino, V. R., Nagel, F., Andreolla, H. F., de-Paris, F., Xavier, M. O., and Goldani, L. Z. (2012). The performance of real-time PCR, galactomannan, and fungal culture in the diagnosis of invasive aspergillosis in ventilated patients with chronic obstructive pulmonary disease (COPD). Mycopathologia 174, 163-169. doi: 10.1007/s11046-012-9531-1

Arvanitis, M., Anagnostou, T., and Mylonakis, E. (2015). Galactomannan and polymerase chain reaction-based screening for invasive aspergillosis among high-risk hematology patients: a diagnostic meta-analysis. Clin. Infect. Dis. 61, 1263-1272. doi: 10.1093/cid/civ555

Arvanitis, M., Ziakas, P. D., Zacharoudakis, I. M., Zervou, F. N., Caliendo, A. M., and Mylonakis, E. (2014). PCR in diagnosis of invasive aspergillosis: a meta-analysis of diagnostic performance. J. Clin. Microbiol. 52, 3731-3742. doi: 10.1128/JCM.1345-14

Blot, S. I., Taccone, F. S., Van den Abeele, A.-M., Bulpa, P., Meersseman, W., Brusselaers, N., et al. (2012). A clinical algorithm to diagnose invasive pulmonary aspergillosis in critically ill patients. Am. J. Respir. Crit. Care Med. 186, 56-64. doi: 10.1164/rccm.201111-1978OC

Buchheidt, D., Reinwald, M., Hofmann, W.-K., Bloch, T., and Siess, B. (2017). Evaluating the use of PCR for diagnosing invasive aspergillosis. Exp. Rev. Mol. Diagn. 17, 603-610. doi: 10.1080/14737159.1325735

Chong, G.-L. M., van de Sande, W. W. J., Dingemans, G. J. H., Gaajetaan, G. R., Vonk, A. G., Hayette, M.-P., et al. (2015). Validation of a new Aspergillus realtime PCR assay for the direct detection of Aspergillus and azole resistance of Aspergillus fumigatus on bronchoalveolar lavage fluid. J. Clin. Microbiol. 53, 868-874. doi: 10.1128/JCM.03216-14

Chong, G. M., van der Beek, M. T., von dem Borne, A., Boelens, J., Steel, E., Kampinga, G. A., et al. (2016). PCR-based detection of Aspergillus fumigatus Cyp51A mutations on bronchoalveolar lavage: a multicentre validation of the AsperGenius assay ${ }^{\circledR}$ in 201 patients with haematological disease suspected for invasive aspergillosis. J. Antimicrob. Chemother. 71, 3528-3535. doi: 10.1093/ $\mathrm{jac} / \mathrm{dkw} 323$

Dannaoui, E., Gabriel, F., Gaboyard, M., Lagardere, G., Audebert, L., Quesne, G., et al. (2017). Molecular diagnosis of invasive aspergillosis and detection of azole resistance by a newly commercialized PCR kit. J. Clin. Microbiol. 55, 3210-3218. doi: 10.1128/JCM.01032-17

Danylo, A., Courtemanche, C., Pelletier, R., and Boudreault, A. A. (2014). Performance of the MycAssay Aspergillus ${ }^{\circledR}$ DNA real-time PCR assay compared with the galactomannan detection assay for the diagnosis of invasive aspergillosis from serum samples. Med. Mycol. 52, 577-583. doi: 10.1093/mmy/ myu025

Dark, P., Blackwood, B., Gates, S., McAuley, D., Perkins, G. D., McMullan, R., et al. (2015). Accuracy of LightCycler ${ }^{\circledR}$ SeptiFast for the detection and identification serum samples than in respiratory specimens. Some data indicate a lower sensitivity in patients with antifungal prophylaxis or treatment.

At the moment, the MycAssay Aspergillus ${ }^{\circledR}$ and the AsperGenius $^{\circledR}$ assay can be recommended for routine PCRdetection of Aspergillus spp. DNA in respiratory samples. It is expectable that more PCR assays will be commercially available in the near future and thus, evaluating (multicenter) studies should also focus on the comparison of different PCR assays. Furthermore, other clinical patient specimens than serum or respiratory secretions should be included in future studies. Cerebrospinal fluid, biopsies, and pleura infusion for example are also relevant specimens for Aspergillus diagnostic.

\section{AUTHOR CONTRIBUTIONS}

P-MR and JS contributed equally by checking the literature and writing the manuscript.

of pathogens in the blood of patients with suspected sepsis: a systematic review and meta-analysis. Int. Care Med. 41, 21-33. doi: 10.1007/s001343553-8

De Pauw, B., Walsh, T. J., Donnelly, J. P., Stevens, D. A., Edwards, J. E., Calandra, T., et al. (2008). Revised definitions of invasive fungal disease from the European organization for the research and treatment of cancer/invasive fungal infections cooperative group and the national institute of allergy and infectious diseases mycoses study group (EORTC/MSG) consensus group. Clin. Infect. Dis. 46, 1813-1821. doi: 10.1086/588660

Denis, J., Forouzanfar, F., Herbrecht, R., Toussaint, E., Kessler, R., and Sabou, M. (2018). Evaluation of two commercial reatl-time PCR kits, A. fumigatus ${ }^{\circledR}$ BioEvolution and MycoGENIE ${ }^{\circledR}$ A. fumigatus for Aspergillus DNA detection in bronchoalveolar lavage fluid in patients with invasive pulmonary aspergillosis. J. Mol. Diagn. [Epub ahead of print].

Green, J., and Dougan, J. A. (2017). “The evaluation of real-time PCR assays for aiding the diagnosis of invasive fungal disease: real-time Aspergillus, and real-time Candida," in Proceedings of the 27th European Congress of Clinical Microbiology and Infectious Diseases, Vienna.

Guegan, H., Robert-Gangneux, F., Camus, C., Belaz, S., Marchand, T., Baldeyrou, M., et al. (2018). Improving the diagnosis of invasive aspergillosis by the detection of Aspergillus in broncho-alveolar lavage fluid: comparison of non-culture-based assays. J. Infect. 76, 196-205. doi: 10.1016/j.jinf.2017. 11.011

Guinea, J., Padilla, C., Escribano, P., Munoz, P., Padilla, B., and Gijón, E. (2013). Evaluation of MycAssay Aspergillus ${ }^{\circledR}$ for diagnosis of invasive pulmonary aspergillosis in patients without hematological cancer. PLoS One 8:e61545. doi: 10.1371/journal.pone.0061545

Lamoth, F., and Calandra, T. (2017). Early diagnosis of invasive mould infections and disease. J. Antimicrob. Chemother. 72(Suppl. 1), i19-i28. doi: 10.1093/jac/ $\mathrm{dkx} 030$

Meersseman, W., Vandecasteele, S. J., Wilmer, A., Verbeken, E., Peetermans, W. E., and Van Wijngaerden, E. (2004). Invasive aspergillosis in critically ill patients without malignancy. Am. J. Respir. Crit. Care Med. 170, 621-625. doi: 10.1164/ rccm.200401-0930C

Montesinos, I., Argudin, M. A., Hites, M., Ahajjam, F., Dodémont, M., and Dagyaran, C. (2017). Culture-based methods and molecular tools for azoleresistant Aspergillus fumigatus detection in a Belgian university hospital. J. Clin. Microbiol. 55, 2391-2399. doi: 10.1128/JCM.00520-17

Morio, F., Dannaoui, E., Chouaki, T., Cateau, E., Malard, O., Bonfils, P., et al. (2018). PCR-based detection of Aspergillus fumigatus and absence of azole resistance due to TR34/L98H in a French multicenter cohort of 137 patients with fungal rhinosinusitis. Mycoses 61, 30-34. doi: 10.1111/myc.12702

Orsi, C. F., Bettua, C., Pini, P., Venturelli, C., La Regina, A., Morace, G., et al. (2015). Detection of Pneumocystis jirovecii and Aspergillus spp. DNA in 
bronchoalveolar lavage fluids by commercial real-time PCR-assays: comparison with conventional diagnostic tests. New Microbiol. 38, 75-84.

Orsi, C. F., Gennari, W., Venturelli, C., La Regina, A., Pecorari, M., and Righi, E. (2012). Performance of 2 commercial real-time polymerase chain reaction assays for the detection of Aspergillus and Pneumocystis DNA in bronchoalveolar lavage fluid samples from critical care patients. Diagn. Microbiol. Infect. Dis. 73, 138-143. doi: 10.1016/j.digmicrobio.2012.03.001

Oz, Y., Aslan, M., Aksit, F., Metintas, S., and Gunduz, E. (2016). The effect of clinical characteristics on the performance of galactomannan and PCR for the diagnosis of invasive aspergillosis in febrile neutropenic patients. Mycoses 59, 86-92. doi: $10.111 /$ myc. 12438

Pini, P., Bettua, C., Orsi, C. F., Venturelli, C., Faglioni, L., Forghieri, F., et al. (2015). Clinical performance of a commercial real-time PCR assay for Aspergillus DNA detection in serum samples from high-risk patients: comparison with a galactomannan enzyme immunoassay. Eur. J. Clin. Microbiol. Infect. Dis. 34, 131-136. doi: 10.1007/s10096-014-2211-y

Schauwvlieghe, A. F. A. D., Vank, A. G., Buddingh, E. P., Hoe, R. A. S., Dalm, V. A., Klaassen, C. H. W., et al. (2017). Detection of azole-susceptible and azole-resistant Aspergillus coinfection by cyp51A PCR amplicon melting curve analysis. J. Antimicrob. Chemother. 72, 3047-3050. doi: 10.1093/jac/dkx262

Steinmann, J., Buer, J., and Rath, P.-M. (2016). Detection of Aspergillus fumigatus in blood samples from critical ill patients in intensive care units by use of the SeptiFast assay. J. Clin. Microbiol. 54, 1918-1921. doi: 10.1128/JCM.00478-16

Steinmann, J., Hamprecht, A., Vehreschild, M. J., Cornely, O. A., Buchheidt, D., Spiess, B., et al. (2015). Emergence of azole-resistant invasive aspergillosis in HSCT recipients in Germany. J. Antimicrob. Chemother. 70, 1522-1526. doi: 10.1093/jac/dku566

Torelli, R., Sanguinetti, M., Moody, A., Pagano, L., Caira, M., De Carolis, E., et al. (2011). Diagnosis of invasive aspergillosis by a commercial real-time PCR assay for Aspergillus DNA in bronchoalveolar lavage fluid samples from high-risk patients compared to a galactomannan enzyme immunoassay. J. Clin. Microbiol. 49, 4273-4278. doi: 10.1128/JCM.05026-11

Verweij, P. E., Chowdhary, A., Melchers, W. J., and Meis, J. F. (2016). Azole resistance in Aspergillus fumigatus: can we retain the clinical use of mold-active antifungal azoles? Clin. Infect. Dis. 62, 362-368. doi: 10.1093/cid/civ885.0
White, P. L., Hibbitts, S. J., Perry, M. D., Green, M. D., Stirling, E., Woodford, L., et al. (2014). Evaluation of a commercially developed semiautomated PCRsurface-enhanced Raman scattering assay for diagnosis of invasive fungal disease. J. Clin. Microbiol. 52, 3536-3543. doi: 10.1128/JCM01135-14

White, P. L., Mengoli, C., Bretagne, S., Cuenca-Estrella, M., Finnstrom, N., Klingspor, L., et al. (2011a). Evaluation of Aspergillus PCR protocols for testing serum specimens. J. Clin. Microbiol. 49, 3842-3848. doi: 10.1128/JCM.05316-11

White, P. L., Perry, M. P., Moody, A., Follett, S. A., Morgan, G., and Barnes, R. A. (2011b). Evaluation of analytic and preliminary clinical performance of Myconostica McAssay Aspergillus ${ }^{\circledR}$ when testing serum specimens for diagnosis of invasive aspergillosis. J. Clin. Microbiol. 49, 2169-2174. doi: 10.1128/JCM.00101-11

White, P. L., Posso, R. B., and Barnes, R. A. (2015a). Analytic and clinical evaluation of the PathoNostics AsperGenius ${ }^{\circledR}$ assay for detection of invasive aspergillosis and resistance to azole antifungal Drugs during testing of serum samples. J. Clin. Microbiol. 53, 2115-2121. doi: 10.1128/JCM.00667-15

White, P. L., Posso, R. B., and Barnes, R. A. (2017). Analytical and clinical evaluation of the PathNostics AsperGenius ${ }^{\circledR}$ Assay for detection of invasive aspergillosis and resistance to azole antifungal drugs directly from plasma samples. J. Clin. Microbiol. 55, 2356-2366. doi: 10.1128/JCM.00411-17

White, P. L., Wingard, J. R., Bretagne, S., Löffler, J., Patterson, T. F., Slavin, M. A., et al. (2015b). Aspergillus polymerase chain reaction: systematic review of evidence for clinical use in comparison with antigen testing. Clin. Infect. Dis. 61, 1293-1303. doi: 10.193/cid/civ507

Conflict of Interest Statement: The authors declare that the research was conducted in the absence of any commercial or financial relationships that could be construed as a potential conflict of interest.

Copyright (๑) 2018 Rath and Steinmann. This is an open-access article distributed under the terms of the Creative Commons Attribution License (CC BY). The use, distribution or reproduction in other forums is permitted, provided the original author(s) and the copyright owner are credited and that the original publication in this journal is cited, in accordance with accepted academic practice. No use, distribution or reproduction is permitted which does not comply with these terms. 